\title{
AS TOURADAS NAS FESTIVIDADES REAIS DO RIO DE JANEIRO COLONIAL
}

\author{
Victor Andrade de Melo \\ Universidade Federal do Rio de Janeiro - Brasil
}

Resumo: Na literatura nacional, já existem muitas discussões sobre as festividades reais promovidas no Brasil colonial. Este artigo tem por objetivo analisar uma das atividades que mais comumente e com maior popularidade integrava a programação desses eventos: as touradas. Que espaços ocupavam nesses festejos? Que símbolos cercavam sua realização? Como eram organizadas? Para responder tais questões, o artigo se debruça sobre as corridas de touros promovidas no Rio de Janeiro, a cidade que se tornara sucessivamente a capital do Vice-Reinado (1763), do Império português (1808), do Reino do Brasil (1815) e do Brasil independente (1822).

Palavras-chave: Brasil colônia, festa, Rio de Janeiro, touradas.

\begin{abstract}
In the national literature, there are many discussions about the royal festivities promoted in colonial Brazil. This article aims to analyze one of the activities that most commonly, with higher popularity, are integrated in the program of these events: bullfighting. What space it occupied in these festivities? What kind of symbols surrounding its achievement? How were organized? To answer these questions, we analyze bullfighting promoted in Rio de Janeiro, the city that became successively the capital of the Vice Royalty (1763), of the Portuguese Empire (1808), of the Kingdom of Brazil (1815) and of the independent Brazil (1822).
\end{abstract}

Keywords: bullfighting, colonial Brazil, festival, Rio de Janeiro.

* Este artigo é um dos resultados do projeto "Sol e sombra: as touradas no Rio de Janeiro", desenvolvido em conjunto com Paulo Francisco Donadio Baptista. 


\section{Introducão}

$\mathrm{Na}$ literatura nacional, já existem muitas discussões sobre as festividades reais promovidas no Brasil colonial. ${ }^{1}$ Organizadas para celebrar datas importantes da Coroa portuguesa, evidenciavam a centralidade do monarca, tendo por intuito acirrar os vínculos de fidelidade com a metrópole. Tratava-se claramente de uma estratégia de controle, de exercício da soberania, a partir de uma exposição simbólica do poder monárquico, que incorporava e unificava o religioso e o político:

As festas públicas mobilizavam todas as esferas da vida política, material, religiosa e simbólica, apresentando-se como vetores importantes de reprodução e reinvenção do modelo societário ibérico em terras do além mar. Momentos de trégua indecisa, de teatralização da ordem social e de dramatização das experiências vividas em comunidades que se viam como parte do Império português, mas, especialmente, como integrantes de um mundo católico. (Kantor, 2008, p. 166).

Essas ocasiões eram importantes para a própria hierarquia colonial, dramatizando a distribuição de poder local, uma situação adequada para o desfile das distinções no palco social: "Nestes momentos festivos a sociedade se apresentava a si mesma, de forma ordenada e ordeira, rememorando os lugares e a soma dos poderes e da autoridade, associados a cada um dos indivíduos que integravam este todo social" (Gouvêa, 2002, p. 152).

Assim, se a organização de uma boa parte das festividades tenha sido uma determinação exarada diretamente de Lisboa, não poucas vezes foram também iniciativas que partiram das câmaras, governadores ou do vice-rei, que procuravam exaltar seus laços de lealdade com a Coroa e publicamente demonstrar seu poder. Não surpreende saber que, após a realização dos festejos, comumente se enviava à metrópole uma prestação de contas do que na colônia ocorrera.

É compreensível que, no Brasil, esses eventos tenham se tornado mais frequentes no decorrer do século XVIII, momento em que cresceram as cidades

1 Ver, por exemplo, os estudos de Hansen (2001), Pereira (2004), Lara (2007), Moura Filha (2007), Paes (2008), entre tantos outros. 
e vilas, período em que aumentou a importância da colônia para a economia de Portugal. De fato, as riquezas minerais, descobertas nessa centúria, foram fundamentais na construção de condições para que a monarquia portuguesa se tornasse mais ostentatória. Esse enriquecimento, inclusive, favoreceu a organização de festividades mais onerosas; o luxo e o fausto reforçavam o poder da metrópole.

Sem negar essa explícita intencionalidade política, parece prudente, todavia, complexificar e ampliar o escopo de análise desses eventos. Se eram quase uma obrigação (e por vezes eram efetivamente uma obrigação), ocasiões instrumentalizadas pelas diversas instâncias de poder, não devemos negar que também eram um momento de diversão, que agradava à maior parte dos envolvidos, tanto mais que, na ordem colonial, as possibilidades de divertimento eram reduzidas, ainda não estavam bem estruturadas e tinham que lidar com uma série de restrições, políticas e religiosas, que iriam se atenuar no decorrer do século XIX.

Os festejos públicos, que envolviam ativamente a população, que participava das mais diversas formas (inclusive com a oferta de donativos que custeavam a organização), possuíam algumas características em comum, entre as quais uma programação que reunia o profano e o sagrado; na esteira do barroco, um conjunto de experiências múltiplas e sensoriais (Conde; Massimi, 2008): cerimônias religiosas, luminárias e fogos de artifícios, representações teatrais que na maior parte das vezes ocorriam em uma arena especificamente montada para a ocasião - a praça do curro. A cidade agitava-se quando eram anunciadas, sempre com alarde, as festividades:

Se o movimento se fazia sentir ativo e vivo nas casas, nas lojas e oficinas, transformando o aspecto patriarcal e tranquilo da cidade, não menos vivo e ativo era o que ia pelos campos indicados para o levantamento de um anfiteatro, onde pudessem ser corridos touros e cavalos, exibidos danças e carros alegóricos. Trabalhavam carapinas vindos de toda parte; pedreiros e pintores de brocha até de madrugada, à luz de cabeças de alcatrão, que a escravaria carregava. E de um amontoado de lonas, de madeiras que carretas cuspiam sem descanso ao redor da praça, surgia, enfim, a grande peça de arquitetura, que se dispunha a impressionar os basbaques do tempo. (Edmundo, 2000, p. 104).

Entre as performances que marcavam a programação dos eventos, além de peças, danças (que com o decorrer do tempo foram adquirindo a 
característica de um desfile de carros alegóricos), atividades musicais e cavalhadas, em muitas ocasiões foram promovidas touradas, assunto que se pretende discutir neste artigo.

Que espaços ocupavam nesses festejos? Que símbolos cercavam sua realização? Como eram organizadas? Para responder tais questões, o artigo se debruça sobre as corridas de touros promovidas no Rio de Janeiro, a cidade que se tornara sucessivamente a capital do Vice-Reinado (a partir de 1763), do Império português (1808), do Reino do Brasil (1815) e do Brasil independente (1822).

\section{Antes da chegada da família real}

As corridas de touros já há muito faziam parte das celebrações em Portugal. Por exemplo, Moura Filha (2007) lembra que, em 1451, em Lisboa, por ocasião dos festejos do casamento da princesa D. Leonor com Frederico III da Alemanha, foi montado um teatro provisório para a realização de touradas. Na verdade, quando se conformou um modelo de festas públicas, que foi para o Brasil transferido, elas passaram a ser concebidas como uma importante parte do espetáculo, com ansiedade aguardada pelo público.

No Rio de Janeiro, ainda que tenham se tornado mais comuns no decorrer do século XVIII, já no XVII foram realizadas por ocasião de algumas festividades. Por exemplo, nas celebrações comemorativas à restauração e aclamação de D. João IV, promovidas entre os dias 31 de março e 8 de abril de 1641, além de encamisadas, comédias, jogo de canas, desfile de companhias de máscara, foram organizadas touradas, em uma praça do curro provavelmente construída na região do Campo da Ajuda: ${ }^{2}$

À terça-feira mandou o Governador correr touros, dando prêmios às melhores sortes, ou maior destreza, tudo à sua custa; e ilustraram a praça muitos cavalheiros que na destreza dos cavalos, brio e força dos rojões livraram o perigo a

\footnotetext{
2 Na verdade, falamos de uma região localizada entre o Morro do Castelo e a Lagoa do Boqueirão, na ocasião ainda não urbanizada nem assim denominada. Isso somente ocorreu com a construção do Convento da Ajuda (em 1750). Também chamado de Largo da Mãe do Bispo, passou por muitas mudanças, sendo hoje a área onde se encontra a Cinelândia. Para uma discussão sobre as cerimônias de 1641, ver Pereira (2004).
} 
que se expunham, sem que sucedesse nem desastre, nem desgosto. (Relação da acclamação..., 1843, p. 351). ${ }^{3}$

Vejamos que esse discurso ecoa algumas representações que acompanham as touradas por toda sua trajetória: o homem que desafia o perigo, que enfrenta a natureza e demonstra publicamente seu valor (Almeida, J., 1951).

Deve-se destacar a importância desse evento nos momentos pós-restauração, em que se sentia a urgência do reestabelecimento de vínculos de lealdade com o Coroa portuguesa. Além disso, no Rio de Janeiro, isso tinha relação com as tensões desencadeadas pela administração de Salvador Correia de Sá e Benevides. ${ }^{4}$ Considerado autoritário, inepto e corrupto, foram intensos os conflitos que ocasionou na cidade.

Já no século XVIII, ainda antes de a cidade tornar-se a capital, as touradas integraram o programa das festividades realizadas no Rio de Janeiro, em 1760, em comemoração ao casamento de D. Maria e D. Pedro. O evento seguiu o modelo habitual: tríduo solene na catedral, luminárias, fogos de artifícios, representações teatrais (farsas, danças, óperas), seis dias de corridas de touros e cavalhadas. Liderou a organização o governador Gomes Freire (Lara, 2007; Pereira, 2004), cuja gestão foi marcada pelo investimento no desenvolvimento urbano.

Esse mesmo governador, juntamente com o bispo D. Antônio do Desterro Malheiros, foi o organizador dos festejos realizados, em 1762, em celebração ao nascimento do Príncipe da Beira, D. José, primogênito de D. Maria I. As touradas foram promovidas em uma praça montada no Campo de São Domingos (Pereira, 2004).

Sobre essas corridas, podemos saber um pouco mais por meio de um opúsculo que narrou as festividades (Relação dos obsequiosos..., 1763), aqui utilizado conforme citado no estudo de Pereira (2004). A praça do curro tratava-se de uma grande instalação, de aproximadamente $73 \times 55$ metros $(40 \times 30$ braçadas), com palanques e dois camarotes luxuosos e muito bem ornamentados. Os símbolos reais estavam espalhados pela arena, bem como exibidos

\footnotetext{
As citações no artigo tiveram sua grafia atualizada para o português contemporâneo.

4 Ocupou vários postos no Império português. Era descendente de Mem de Sá e Estácio de Sá, fundadores da cidade. Foi governador do Rio de Janeiro em três períodos: 1637 a 1642, 1648 e 1659 a 1660. Para mais informações, ver Fragoso (2003) e Silva (2005).
} 
nas pomposas roupas dos mais poderosos. Estima-se que, por dia, cerca de 10 mil pessoas compareceram ao evento, entre as quais as mais importantes personalidades da cidade. Para que se tenha uma ideia do tamanho da afluência de público, segundo Honorato (2008), em 1799, mais de 35 anos depois, portanto, o Rio de Janeiro possuía 43.736 habitantes.

É possível perceber que as touradas seguiram, na íntegra, o ritual típico português, destacando-se a atuação do diretor da companhia de toureiros, o sargento-mor Gregório de Morais Castro Pimentel. Percebe-se que já havia alguma estrutura comercial ao redor das corridas, mesmo que ainda se estivesse longe do formato que vai marcar a prática a partir da terceira década do século XIX. Por exemplo, não se tratava de um grupo tauromáquico profissional e estável, mas sim formado para a ocasião (e mesmo para situações em que havia corridas de touros isoladas). De toda forma, não atuavam gratuitamente, eram remunerados por sua performance.

Vale a pena dedicar algumas linhas para discutir a participação do sargento-mor como diretor da companhia de toureiros. Devemos lembrar que, na ocasião, tratava-se de uma patente de oficial superior, aproximadamente equivalente ao atual posto de major. Gregório Pimentel alcançara tal condição por sugestão do próprio Gomes Freire, que já o conhecia de situações particulares. Futuramente chegaria a coronel, tendo se aposentado como brigadeiro (logo abaixo de general). Esteve, entre outras ações relevantes, envolvido com o estabelecimento de fronteiras em decorrência do Tratado de Madri (1750). ${ }^{5}$ Foi, enfim, um personagem de destaque na sociedade colonial que assumiu uma função protagonista nas touradas de 1762 .

Como já observamos, os festejos eram também realizados quando havia alguma importante ocasião local, como a posse de governantes. Luiz Edmundo (2000) sugere que uma dessas situações pode ser observada, em 1769, nas celebrações oferecidas pelo Conde de Azambuja ${ }^{6}$ ao Marquês de Lavradio, ${ }^{7}$ no momento em que o último tornou-se o novo vice-rei.

Lavradio não parece ter ficado muito satisfeito com a recepção, a despeito de reconhecer a boa organização do evento:

\footnotetext{
Substituindo o Tratado de Tordesilhas, definiu os limites entre as colonias sul-americanas de Portugal e Espanha.

6 Foi vice-rei do Brasil entre 1767 e 1769.

7 Foi vice-rei do Brasil entre 1769 e 1778.
}

Horizontes Antropológicos, Porto Alegre, ano 19, n. 40, p. 365-392, jul./dez. 2013 
Houve seis dias de luminárias e algumas ruas estavam magníficas porque além das luzes que havia nas janelas eram lustres pelo meio da rua e em uma noite em que fui com o conde vice-rei ver este obséquio o acrescentaram com bastante fogo de artifício e muito fogo do ar. Tem havido três dias de outeiro e outros três de ópera, alternando estes dois divertimentos entre si, e prevenida uma grande festa de touros e cavalhadas para o que se está acabando uma praça que ficará magnífica; porém, todos esses divertimentos e todas essas podres e abomináveis bajulações não têm tido o poder de me fazer satisfação nem por um instante. ${ }^{8}$

Sugere Edmundo (2000) que Lavradio não era afeito a touradas, e não teria especialmente apreciado as atividades realizadas na praça do curro montada no Campo de São Domingos. De um lado, isso pode parecer estranho já que o novo vice-rei demonstrava uma grande disposição para a vida social, sendo costumeiro frequentador de bailes e reuniões sociais, bem como fervoroso colaborador para o desenvolvimento do teatro (Cavalcanti, 2004). De outro lado, vale lembrar que era muito preocupado com o progresso e com os avanços dos costumes, tendo desempenhado efetivamente um importante papel na melhor estruturação da colônia, notadamente da capital. ${ }^{9}$

A proximidade de Lavradio com ideais iluministas e com as ideias do Marquês de Pombal ${ }^{10}$ pode ajudar a entender sua não adesão às corridas de touros. Elas estariam muito ligadas a certas representações que algumas lideranças políticas pretendiam superar. Lembremos que, em 1777, chegou-se a proibir as touradas em Portugal, uma decisão que não foi à frente, ainda que tenha posto em xeque o hábito de matar o touro na arena (Almeida, J., 1951).

$\mathrm{O}$ fato é que as contestações podem até ter interferido na dinâmica da prática, mas não destruíram seu prestígio. A arte de tourear vai mesmo marcar a construção do "marialvismo", termo que se origina do livro lançado pelo Marquês de Marialva, um dos que lançou as bases do toureio a cavalo. Trata-se de uma noção que vai se conformar como uma tradição conservadora: o provinciano em oposição ao citadino, uma contraposição ao libertino, a

\footnotetext{
Correspondência particular do vice-rei marquês do Lavradio. Arquivo do senhor Hipólito Santos. Carta de amizade escrita ao chanceler conselheiro na Bahia, em 8 de dezembro de 1769.

9 Um panorama de suas ações pode ser percebido em Arquivo Nacional (1999).

${ }_{10}$ Pombal foi secretário de Estado do Reino durante o reinado de D. José I (1750-1777). Foi um dos propugnadores da adoção de ideias ilustradas em Portugal.
} 
proposição de se afastar de parâmetros europeus ilustrados. Marca, de fato, uma especificidade na construção identitária portuguesa (Almeida, M., 1997).

No Rio de Janeiro, uma vez mais as corridas foram inseridas na programação das festividades realizadas para a celebração do casamento de D. João com D. Carlota Joaquina, em 1786, organizadas pelo vice-rei Luís de Vasconcelos e Sousa. ${ }^{11}$ A maior parte das instalações das comemorações foi montada no Passeio Público, um novo espaço que simbolizava as iniciativas, tímidas é verdade, de modernização da cidade. Para Vieira Fazenda (1921), a arena foi construída bem ao lado do novo parque, no Campo da Lapa do Desterro. $^{12}$

Para Segawa (1996), chega a ser surpreendente a criação de um local tão "civilizado" em plena ordem colonial. Nesse sentido, é mesmo possível que por lá não se tenham realizado touradas. É mais provável que esteja certa Lara (2007), que sugere que a arena na qual se realizaram os festejos de 1786 tenha sido instalada no Campo de Santana, local que passou a abrigar a maior parte das corridas até 1822 .

Tratava-se, na época, de uma região mais afastada do centro do Rio de Janeiro. Chamou-se Campo de São Domingos por lá haver uma capela ao santo dedicada. A partir de meados do século XVIII, com a construção de um novo templo, passou a ser também conhecido como Campo de Santana. Durante muito tempo foi uma área deserta, dedicada ao pasto ou usada para jogar os dejetos, o limite entre o urbano e o rural.

No decorrer do século XIX, o espaço foi sendo reestruturado e ao seu redor foram instaladas importantes edificações. Simultaneamente, foi se tornando um jardim, dividindo as atenções com o Passeio Público. Passou também a sediar festividades e eventos. ${ }^{13}$ Como sugere Segawa (1996, p. 159):

A criação de um jardim de amenidades e festejos [...] - alternativo ao Passeio Público setecentista - indiciava o papel relevante e oficial que o Campo de Santana gradativamente iria assumindo ao longo do século 19. Efetivamente,

${ }^{11}$ Como seu antecessor, o marquês de Lavradio, destacou-se por sua ligação a ideias ilustradas. Foi vice-rei de 1778 a 1790.

${ }^{12}$ Atual Largo da Lapa, na época assim denominado em função da Igreja de Nossa Senhora da Lapa do Desterro, construída em 1750.

${ }^{13}$ Mudou de nome várias vezes até ser denominado Praça da República (embora continue sendo conhecido como Campo de Santana). 
a Corte elegeu - e a família imperial brasileira endossou - aquele espaço como cenário de suas exibições de pompa e circunstância em diversas oportunidades.

Lá foi montada a praça do curro para as comemorações do nascimento de D. Francisco Antônio (1795), primeiro filho homem de D. João e D. Carlota Joaquina $^{14}$ (Pereira, 2004). Na obra de Cavalcanti (2004), encontramos uma preciosa relação das despesas do Senado da Câmara na preparação dessas festividades. Percebe-se que eram altos os custos e grandes as exigências técnicas. Foram gastos quase 6:000\$000 (seis contos de réis) com a compra de material para a construção da arena, a contratação de pessoal para executar as obras e desempenhar todas as funções necessárias, a aquisição de material diverso (entre os quais para as vestimentas de dois toureiros, Luiz Antônio e Joaquim Ferreira $\left.{ }^{15}\right)$.

Cavalcanti (2004) informa também que, entre os profissionais de artes cênicas que na ocasião trabalhavam na cidade, Luiz Antônio Gonzaga era um empresário que organizava touradas. Não consegui mais informações sobre esse personagem, mas esse dado é mais um indício de que alguma estrutura comercial já cercava as corridas de touros.

\section{Após a chegada da família real}

Em 1808, em função dos conflitos napoleônicos, a família real portuguesa desembarcou no Brasil. O inusitado fato de o Rio de Janeiro ter se transformado na capital do Império português, bem como a ascensão do Brasil à condição de Reino Unido ao de Portugal e Algarves (1815) e a própria coroação de D. João VI (1818), que se deu em terras brasileiras, contribuíram tanto para desenvolver um protagonismo político local quanto para potencializar os mercados interno e externo já existentes desde o século XVIII (Caldeira, 2011).

\footnotetext{
${ }^{14}$ Francisco Antônio faleceu em 1801, abrindo caminho para D. Pedro tornar-se herdeiro do trono.

15 O material comprado permite-nos ter uma noção das vestimentas: veludo cor-de-rosa, verde, preto; seda pérola ramo de ouro, chapéu fino liso sabido, chapéu fino de dois galões, galão de prata, galão de prata para chapéu, ourante escarlate, bertanha saluzia, calças, maqueduns, tafetá cor de pérola, holanda, holanda crua, holandilha, lenço para pescoço, fita de lágrimas, jaleco bordado de matiz, retrós, linha, botões, marcas, forçal (Cavalcanti, 2004).
} 
Até 1820, quando ocorre a Revolução Liberal do Porto, o que se percebe é um acirrar das relações com a ordem monárquica, uma vez mais celebrada pelas muitas festas públicas organizadas, diretamente relacionadas a datas importantes da família real. As touradas seguem sendo uma atividade importante nessas ocasiões. Como celebra Luiz Gonçalves Santos (1981, p. 17), ${ }^{16}$ o Padre Perereca, cuja obra é marcada por um tom bajulador:

Foi um tempo de solenidades faustosas, de frequentes cerimônias religiosas, de procissões votivas, touradas, cavalgatas e encamisadas, com o pitoresco dos costumes - em dias de gala, de aniversários e batizados de pessoas reais ou de fidalgos, concorrendo o povo a esses divertimentos, que se revestiam de pompa até então desconhecida.

Como no período anterior, é importante observar que esses eventos, ainda que marcados por fortes intencionalidades políticas, eram ocasiões que adquiriam sentidos multifacetados:

Não se pode encarar a noção de festejo público apenas como uma forma de mistificação política ou social. O povo aprende a respeitar o soberano, mas ao mesmo tempo diverte-se; o povo fica entretido e, portanto, tranquilo, mas ao mesmo tempo que é espectador, ele participa do festejo. (Silva, 1978, p. 57).

Já na chegada da família real, foram magníficas as cerimônias de recepção. Na programação, como de costume, houve touradas. ${ }^{17}$ Nessa ocasião, se destacou o envolvimento de certos personagens que, desempenhando funções subalternas (notadamente ligadas à lida com cavalos e ao artesanato de cobre e ferro), passariam a ocupar um espaço protagonista nos festejos públicos: os ciganos.

Desde o início do século XVIII, os ciganos começaram a chegar ao Brasil, a princípio por terem sido degradados de Portugal. No Rio de Janeiro, uma das localidades em que se instalaram foi o Campo dos Ciganos, o antigo Largo do Rossio Grande, depois renomeado para Campo do Polé, Praça da Constituição e, por fim, Praça Tiradentes. Nessa área, por ocasião da elevação do Brasil a

\footnotetext{
${ }^{16}$ A edição original dessa obra é de 1825 .

17 Para um breve panorama dessas comemorações, ver Schwarcz, Costa e Azevedo (2002).
} 
Reino Unido, em 1815, foi realizada parte significativa dos festejos, nos quais os ciganos desempenharam importante papel, inclusive nas touradas. ${ }^{18}$

Uma das mais notáveis ocasiões em que as corridas de touros integraram a programação de festividades organizadas na capital se deu em 1810, nas cerimônias de celebração do casamento de D. Pedro Carlos de Bourbon e Bragança, infante da Espanha, e D. Maria Teresa, filha mais velha de D. João e D. Carlota Joaquina. Foram sete dias de touradas, cavalhadas, danças, desfiles de carros e espetáculos de fogos de artifício. A Gazeta do Rio de Janeiro estima que cerca de 7 mil pessoas tenham comparecido por dia. A celebração foi intensa, com o intuito de dar provas "do muito Amor e Respeito que o honrado Povo do Rio de Janeiro consagra à Augustíssima Família de Bragança, que tanto bens lhe veio trazer com sua Presença" (Gazeta do Rio de Janeiro, 1810a, p. 3, grifo no original). Para Santos (1981), tratou-se de uma das mais empolgantes festividades até então promovidas. ${ }^{19}$ Ainda que as funções tenham se repetido por dias, sugere nosso informante que não foi possível atender a todos os interessados. O próprio príncipe regente teria determinado que parte das atividades fosse reproduzida fora da praça de curro, para que maior número de pessoas pudessem assistir. A Gazeta do Rio de Janeiro (1810b, p. 4) celebra essa decisão:

Tal é o paternal desvelo de S. A. R. pelo seu amado Povo, que não só se ocupa em grande dos seus mais caros interesses, prosperando o Comércio, Fábricas, e Lavoura, e procurando a paz e cômodo de todos; mas sem lhe escapar coisa alguma, chega a ponto de se dignar concorrer para que não falte aos pequeninos ocasião de se entreterem com um espetáculo deleitável.

Segundo Santos (1981, p. 263), a arena construída para essa cerimônia, "pela sua extensão, grandeza e elegância, levou a palma a todas quantas jamais se fizeram nesta cidade". Tratava-se de uma instalação poligonal de 12 lados, quase oval, com comprimento de 474 palmos, largura de 351 palmos e altura de 40 palmos; isso é, aproximadamente $105 \times 77$ x 9 metros. O interior

18 Posteriormente também se instalaram na Cidade Nova, nas redondezas do Campo de Santana, e tomaram parte nas atividades tauromáquicas que nesse local se organizaram. Para mais informações sobre os ciganos, ver Moraes Filho (1981).

19 Deve-se perceber que o inglês John Luccock (1987) não se mostrou tão empolgado como Santos (1981). $\mathrm{Na}$ verdade, as considerou modestas e longe das suas congêneres europeias.

Horizontes Antropológicos, Porto Alegre, ano 19, n. 40, p. 365-392, jul./dez. 2013 
era ricamente adornado, com muito conforto nos camarotes. Mesmo que devamos descontar certo exagero do nosso informante, o Padre Perereca, não se pode negar o fausto e o investimento.

De acordo com a Gazeta do Rio de Janeiro (1810b, p. 2), o redondel era "admirável pelo seu tamanho, elegância, e cômodo, e que pelo assíduo zelo do respeitável, e digno Magistrado, que preside a Polícia, foi feito de propósito para as festas sem despesa de pessoa alguma, e em tempo incrível pela brevidade". De fato, ficara responsável pela organização Paulo Fernandes Vianna, intendente-geral de polícia, um cargo que, na época, tinha funções similares às de um prefeito, além do exercício das tarefas de segurança pública.

Na maior parte das vezes, todavia, o Senado da Câmara era responsável pela promoção das festividades, tanto pelas ordinárias (isso é, aquelas que ocorriam com certa frequência, como as religiosas) quanto pelas reais (que ocorriam de acordo com a determinação da monarquia) ${ }^{20}$ Deveria conseguir os recursos e estruturar tudo o que fosse necessário para a boa realização dos eventos, inclusive contratando os serviços adequados.

Nem sempre era simples cumprir essa função. Havia constantemente conflitos de interesses, já que os mais poderosos da cidade buscavam assumir um papel protagonista, reforçando sua notabilidade social: com a Coroa, com a elite local, com a própria população. Como vimos no caso da atuação de Paulo Vianna nos festejos de 1810, por vezes o Senado da Câmara era mesmo alijado da organização. Havia também dificuldades de ordem financeira. Vejamos o envolvimento da instituição na promoção das festividades de outubro de 1818.

Esse foi mesmo um ano animado. Já no mês de janeiro foram organizadas festividades para comemorar o aniversário da nova princesa real, a austríaca D. Carolina Josefa Leopoldina, que chegara ao Brasil no final de 1817, em função de seu casamento com D. Pedro (que futuramente seria o primeiro monarca do país independente). Em frente ao Palácio de São Cristóvão, na Quinta da Boavista, foi montada a praça de curros. Em meio a apresentações musicais, teatrais e de danças, sempre com muitos fogos artifícios, ocorreram

${ }^{20}$ De acordo com Gouvêa (2002, p. 127), três eram as principais funções do Senado da Câmara: a indicação dos habilitados para os cargos de confiança, o abastecimento da cidade e "a organização de boa parte das cerimônias e dos divertimentos que entretinham a população". Para mais informações sobre o Senado da Câmara, ver Porto (2011).

Horizontes Antropológicos, Porto Alegre, ano 19, n. 40, p. 365-392, jul./dez. 2013 
quatro tardes de corridas de touros (Norton, 2008; Santos, 1981). Maria Graham (1956, p. 56) faz referência a essa ocasião:

Este ano abriu-se no Rio com uma festa incomum. A 22 de janeiro houve uma grande tourada em São Cristóvão - a casa de campo real - em honra do aniversário da jovem Princesa Real. Seguiu-se uma dança militar na qual se exibiram os vestuários de cada região dos domínios portugueses a leste e oeste. Apareceram Portugal, Algarve, África e Índia, China e Brasil para homenagear a ilustre estrangeira. A música, em que o gosto do rei era incomparável, formava uma grande parte do espetáculo e o Brasil talvez nunca tenha tido um festival tão magnífico. ${ }^{21}$

A Gazeta do Rio de Janeiro também não poupou tinta para elogiar os festejos, inclusive as corridas de touros. O jornal observa que: "Assistiu a estes belos espetáculos um imenso concurso de povo, a quem foi concedida a sublime honra de acompanhar a Sua Majestade" (Gazeta do Rio de Janeiro, 1818a, p. 3). O evento, como de costume, serviu para que a família real se exibisse para o público, em seus camarotes próprios, acompanhada de diplomatas, oficiais, membros das elites. Além de tudo, aproveitou-se a ocasião para apresentar D. Leopoldina à sociedade da corte.

O melhor estava por vir. Entre os meses de fevereiro e outubro ocorreram na cidade várias comemorações relacionadas a duas importantes cerimônias monárquicas realizadas em solo brasileiro: a aclamação de D. João como rei de Portugal, Brasil e Algarves e o casamento de D. Pedro e D. Leopoldina.

Foram intensos os preparativos para a culminação das festividades, uma grande festa a ser realizada em outubro. Essa movimentação recebeu uma breve observação do mal-humorado Luís Joaquim dos Santos Marrocos, que chegara à cidade, em 1811, trazendo de Lisboa a Biblioteca Real, tornando-se responsável por esse acervo e por organizar os documentos da Coroa. Segundo suas palavras, em função do evento, chegava muita gente das capitanias, realizavam-se muitos ensaios e recebia-se na capital os mais diversos produtos: "mandaram vir grossas manadas de touros escolhidos em força e braveza, com que se pretende dar as boas tardes a uns e boas noites a outros" (Marrocos, 2008, p. 398).

${ }^{21}$ Essa obra foi pela primeira vez publicada em 1824 . 
$\mathrm{Na}$ verdade, desde 1817, a celebração estava sendo preparada. Em reunião realizada em 11 de novembro, o Senado da Câmara começara a se organizar, inclusive convocando as corporações de ofícios ${ }^{22}$ a participarem das cerimônias, tendo acordado que "se construísse um Curro no Campo de Santana", com todo "embelezamento e fausto de um objeto de tanta consideração e respeito". ${ }^{23}$

Já se discutiu o quanto a construção da praça do curro era custosa, complexa e preocupava os responsáveis pela organização das festividades. Era o sinal mais evidente do poderio da monarquia, que não deveria se exibir em uma instalação improvisada e mal-acabada. Dada essa importância, não surpreende saber que por ela ficaram responsáveis importantes personagens da engenharia colonial. Por exemplo, a arena que recebeu os festejos de 1818 foi planejada por Grandjean de Montigny, sendo as obras orientadas por Manuel Costa.

O envolvimento desses personagens é mais uma prova da importância da empreitada. O primeiro chegara ao Brasil junto com a Missão Artística Francesa e foi um dos responsáveis por difundir na colônia (e depois no país independente) um corpo de conhecimentos e profissionais sobre a arquitetura. Já o segundo foi um dos artistas que acompanhou D. João em sua vinda para a América. Foi o arquiteto de importantes obras, como o Teatro Real de São João e o Palácio de São Cristóvão.

Mas com quais recursos o Senado da Câmara promoveria os eventos? Não é fácil obter, com precisão, informações sobre as rendas e despesas da instituição. Sabe-se que, todavia, parte significativa de seus recursos era destinada às festividades (Gouvêa, 2002).

Para os festejos de 1818, a Câmara lançou um edital para a construção da praça do curro. Todavia, como podemos ver na descrição da reunião de 13 de dezembro de 1817 , não considerou adequadas e suficientes as propostas apresentadas. Dessa forma, decidiu "por se fazer o Curro por administração e

\footnotetext{
${ }^{22}$ Na ocasião, parecia ainda vigorar a organização portuguesa das corporações de ofícios (Nova Regulação da Casa dos Vinte e Quatro): 12 grêmios ligados às diversas categorias profissionais. Para mais informações, ver Martins (2008).

23 Arquivo Geral da Cidade do Rio de Janeiro, Vereanças 1817, códice 16-3-25.
} 
conta do mesmo Senado que para os meios e circunstância necessárias para a sua fatura se ajam". ${ }^{24}$

No entanto, os vereadores tinham que lidar com os problemas econômicos que sempre marcaram a instituição, acentuados com as exigências que sobre ela se abateram com a chegada da Família Real (Gouvêa, 2002). Assim, ficou decidido que todas as rendas em caixa ficariam destinadas à construção do curro. Mais ainda, para garantir a excelência das festividades, optou-se por fazer um fundo de 32:000\$000, com cotas divididas por quatro vereadores (oito contos de réis para cada). Mesmo assim, os recursos parecem não ter sido suficientes.

A solução para as despesas veio de um antigo procedimento. Dando provas de "sua lealdade e vassalagem para com a Coroa, através da disponibilização de seus recursos pessoais" (Gouvêa, 2002, p. 117), os vereadores Francisco de Souza e Oliveira, Luiz José Viana Gurgel do Amaral e Rocha e o Coronel Manoel Caetano Pinto emprestaram, cada um, mais 2:000\$000.25

Nas atas de 1818, podem-se perceber algumas das despesas previstas. Em 2 de maio, ${ }^{26}$ identifica-se que da Capitania de São Paulo pretendia-se comprar 30 touros, prevendo-se também convidar para dirigir as corridas o capitão-mor da Vila de Castro, Domingos José Vieira. ${ }^{27}$ Em 17 de junho, informa-se que se tentou também adquirir esses animais em São João Del Rei. Mais ainda, que o Brigadeiro Francisco Xavier dos Santos ${ }^{28}$ estimara em 250\$000 o custo com a equipe de toureiros.

Eram mesmo custosas essas festividades. No Rio de Janeiro, o pagamento das dívidas se arrastou por quase um ano. Por exemplo, somente em 28 de abril de 1819, a vereação autorizou a pagar 18\$530 a Francisco Estanislau de Oliveira, por ter cobrado $926 \$ 602$ das diversas corporações que se propuseram a ajudar. ${ }^{29}$ Em 9 de junho foi a vez dos paulistas cobrarem o dinheiro dos touros.

\footnotetext{
24 Arquivo Geral da Cidade do Rio de Janeiro, Vereanças 1817, códice 16-3-25.

${ }^{25}$ Arquivo Geral da Cidade do Rio de Janeiro, Vereanças 1818, códice 16-3-25. Sessões de 8 de agosto de 1818, 19 de agosto de 1818 e 22 de agosto de 1818 .

26 Arquivo Geral da Cidade do Rio de Janeiro, Vereanças 1818, códice 16-3-25.

27 Provavelmente refere-se ao filho homônimo do também capitão-mor Domingos José Vieira, um dos fundadores de Itapetinga, falecido em 1799. Percebe-se que continua sendo um personagem de importância o diretor da companhia de toureiros.

28 Dono da Chácara do Chá, em São Paulo, era um dos mais ricos homens daquela província.

29 Arquivo Geral da Cidade do Rio de Janeiro, Vereanças 1819, códice 16-3-25.
} 
Depois de uma longa e exaustiva preparação, parece terem sido um sucesso as festividades de outubro de 1818, nas quais as touradas, como de costume, estiveram inseridas em uma programação diversa. $\mathrm{O}$ afluxo de público foi notável. Como sugere Silva (1978, p. 64):

Quer as corridas de touros, quer as cavalhadas, eram consideradas a parte nobre do espetáculo na praça de curro, e às vezes realizavam-se umas, às vezes outras, pois os festejos duravam vários dias [...]. A repetição era aliás necessária para permitir que maior número de pessoas pudesse presenciar nas bancadas as corridas $[\ldots]$.

De fato, a Gazeta do Rio de Janeiro (1818b, p. 1) informa que as cavalhadas e corridas de touros ocuparam um grande espaço na programação:

Desejando o Senado da Câmara desta Cidade manifestar o júbilo de todos os seus habitantes pelos felicíssimos desposórios de SS. AA. RR. o Príncipe Real do Reino Unido de Portugal, do Brasil e Algarves com a Sereníssima Senhora CAROLINA JOSEFA LEOPOLDINA, Arquiduquesa da Áustria, mandou erigir, no vastíssimo Campo de Santana, uma praça magnífica, construída com o mais apurado gosto, a fim de dar ao povo em públicos divertimentos por seis dias sucessivos de touros, e cavalhadas interpoladamente, um dilatado teatro para ostentar seus leais sentimentos.

As corridas de touros seguiram todos os rituais. Segundo Oliveira Lima (2006, p. 563), ${ }^{30}$ os cavaleiros estavam vestidos: "à antiga portuguesa, de casaco de veludo bordado com bofes de renda e chapéu tricorne, montados nos estribos de caixa sobre cavalos de boa raça e vistosamente ajaezados".

De acordo com a minuciosa descrição de Santos (1981), o modelo da arena era muito similar aos anteriores, mas a construção era ainda mais refinada. Possuía $610 \times 353$ x 77,5 palmos (isso é, $134 \times 78 \times 17$ metros) e fora muito elogiada por todos. Segundo Oliveira Lima (2006, p. 565): "Escrevia Maler - e o elogio não é fraco - que o Campo de Sant'Ana exibia brilho e gosto suficientes para fazer pensar nas Tulherias e nos Campos Eliseus, quando

${ }^{30}$ A primeira edição desse livro é de 1908.

Horizontes Antropológicos, Porto Alegre, ano 19, n. 40, p. 365-392, jul./dez. 2013 
iluminados." Segundo a descrição de Vieira Fazenda (1921, p. 539), provavelmente extraída de uma notícia publicada na Gazeta de Lisboa: ${ }^{31}$

No centro apresentava um largo espaço de forma elítica, destinado propriamente aos festejos. Uma tela, rezam os jornais do tempo e repete o padre Luiz Gonçalves, de seis e meio palmos de altura, defendia a grande bancada, a qual, dividida por quatro coretos, torneava toda a praça, começando e terminando em um majestoso pórtico representando um arco triunfal. Este estava firmado sobre quatro colunas, por cima das quais pousava a cimalha geral, que dali circundava toda a praça.

Enfim, ainda mais do que no período colonial, as touradas, integrando as festividades reais, lograram sucesso e serviram, de forma multifacetada e não poucas vezes tensa, aos diferentes interesses existentes na capital do Império português.

\section{Às vésperas da independência}

A Revolução do Porto, ocorrida em 1820, estabeleceu, entre outras coisas, duas decisões que tiveram imediato impacto no Brasil: o retorno imediato da família real a Portugal (o que se deu em 1821) e a restauração de exclusividade de comércio entre a colônia e a metrópole.

As cortes foram convocadas em 1821 e sua postura, no sentido de fazer o Brasil retroagir a seu antigo estatuto colonial, acabaram fortalecendo teses independentistas. Em setembro de 1822, a antiga colônia proclama sua emancipação, dando início a uma nova fase em sua trajetória.

Os anos em que a família real esteve instalada no Rio de Janeiro foram fartos de mudanças para a cidade. Deve-se ter em conta que, a despeito das modificações perceptíveis desde as últimas décadas do século XVIII, a sua estrutura urbana ainda era muito acanhada por ocasião da chegada da corte portuguesa, inclusive no que se refere aos divertimentos. A partir dos anos 1810, começa a melhor se organizar, entre outras, essa dimensão na capital, inclusive em função do aumento do número de estrangeiros, que tentavam minimizar o que consideram uma "vida monótona". Inicialmente ampliaram-se

31 Cf. Gazeta de Lisboa (1819, p. 2). 
as alternativas privadas de entretenimento, como os bailes e recepções nas casas. ${ }^{32}$

Vale uma referência à fundação da Assembleia Portuguesa, em 1815, a primeira sociedade de recreio da cidade, autorizada por licença real, contando entre seus sócios com membros das elites, alguns dos quais também já envolvidos com o funcionamento do Teatro São João (Silva, 1978). As preocupações com o teatro, aliás, também se tornaram mais relevantes, inseridas nas iniciativas de adequar o Rio de Janeiro ao que se esperava de uma capital de Império. No que tange a outros divertimentos públicos, ainda seriam necessários mais alguns anos para estruturação. Vejamos o que se passou com as touradas nos últimos anos do período colonial.

Em 1819, continuava construída, no Campo de Santana, a praça do curro. Assim a ela se referem Leithold e Rango (1966, p. 12): ${ }^{33}$ "De um lado, e não exatamente no meio, está um grande circo de madeira, onde se realizam as touradas; do outro lado, um grande jardim não sombreado e raramente visitado, em que há umas estátuas de madeira, pintadas."

Nessa mesma obra, quando comentam como, na ocasião, o teatro era a principal opção de diversão no Rio de Janeiro, Leithold e Rango observam que, ainda que apreciadas, em 1819 somente houve touradas em uma ocasião, nas celebrações do nascimento da princesa Maria da Glória.

No seu ponto de vista, essas touradas foram um verdadeiro fiasco, tanto que o público (segundo eles formado por "portugueses, brasileiros, mulatos e negros"), vaiou todo o tempo:

Um tourinho magro, cuja ira alguns figurantes paramentados procuravam em vão provocar com suas capas vermelhas, permanecia fleumático e, quando parecia uma vez que outra disposto a investir, logo pulavam eles assustados a barreira que os separa do público e eram recebidos com assobios e cascas de laranja. (Leithold; Rango, 1966, p. 17).

32 Para mais informações, ver Schultz (2008) e Schwarcz (2011).

${ }^{33}$ Leithold e Rango (tio e sobrinho) foram dois dos muitos viajantes que pelo Rio de Janeiro estiveram nas primeiras décadas do século XIX. Tendo ficado pouco tempo na cidade, por falta de adaptação, suas posições em geral são muito apressadas e pouco favoráveis ao que viram. O livro foi publicado originalmente em 1820.

Horizontes Antropológicos, Porto Alegre, ano 19, n. 40, p. 365-392, jul./dez. 2013 
O mesmo teria ocorrido com vários outros animais, despertando a ira da assistência, que não se conformava que o organizador não tivesse conseguido bons animais, até porque: "Os camarotes haviam sido todos vendidos a preços altos e as arquibancadas acomodavam incrível multidão de todas as classes." (Leithold; Rango, 1966, p. 17).

Algumas dessas dimensões vão cercar as touradas em sua trajetória no decorrer do século XIX: a baixa qualidade dos touros e a má organização das corridas. Em 1819, isso poderia ter relação tanto com a falta de recursos para promover boas festividades quanto com a tensa situação política em Portugal, o que tinha impactos no Brasil. Há que se destacar também uma mudança na dinâmica. Ainda que ligada a uma cerimônia da família real, tratou-se de um modelo mais "empresarial" de organização, com menor participação dos cofres públicos.

$\mathrm{Na}$ verdade, a partir de 1818 , a praça de curro passou a não servir exclusivamente às festividades governamentais, sendo também utilizada por empresários para promover atividades diversas, entre as quais exibições de acrobacia, ginástica e circos de cavalos (Silva, 1978).

Vejamos que o Senado da Câmara, em 23 de novembro de 1818, mandara avisar a Fernando José de Almeida que estava aberto o arrendamento da praça até a data do entrudo. Esperava-se receber 5:000\$000, metade à vista e o restante em 60 dias. $^{34}$

Fernando José de Almeida foi um personagem controvertido. Chegou ao Rio de Janeiro na condição de cabelereiro do Vice-Rei D. Fernando José de Portugal e Castro. Logo se envolveu, já com as benesses do Príncipe Regente, com o projeto da construção de um teatro adequado para a cidade, o São João, erguido no Largo do Rossio. ${ }^{35}$ Por sua proximidade com o poder, pelo envolvimento com a atividade teatral e pela relação que já se estabelecia entre o teatro e as touradas, entretenimentos apreciados pela população, lembrou-se do seu nome para dirigir as atividades na praça do curro.

34 Arquivo Geral da Cidade do Rio de Janeiro, Vereanças 1818, códice 16-3-25.

35 Inaugurado em 1813, tornou-se o maior e mais badalado teatro da colônia. Incendiou-se em 1823 e foi reconstruído e reinaugurado, pelo mesmo empresário, em 1828, já renomeado como São Pedro de Alcântara. Depois de muitas idas e vindas, hoje, no mesmo local, na Praça Tiradentes, existe o Teatro João Caetano. 
Ao fim, todavia, a arena foi arrendada por José Inácio da Costa Florim. ${ }^{36}$ Em 1819, tal cessão foi renovada por seis anos, pela quantia de 13:000\$000. Teria ele promovido touradas? Não consegui comprovações, mas é possível que estivesse por trás das já citadas corridas de 1819. Além disso, encontrei outro indício na Gazeta do Rio de Janeiro de 8 de janeiro de 1820: o comerciante anunciou que pretendia promover "um combate de touros da melhor escolha" (Gazeta do Rio de Janeiro, 1820, p. 4). Participava da iniciativa uma insigne personalidade da colônia àquele momento, o sargento-mor Joaquim Moreira da Costa, dono de rebanhos na região de Sorocaba, comerciante de gado para abastecimento da capital (Garrido, 2012).

Florim não ficaria muito tempo mais à frente do empreendimento. Em 1821, uma determinação régia ordenou o desmanche da praça do curro, o obrigando a assinar um destrato. De acordo com Segawa (1996), fora uma decisão de Pedro I, supostamente por rivalidades políticas com o intendente Paulo Fernandes Vianna, que muito se empenhara nas reformas do Campo de Santana. Para Henderson (1821), tinha a ver com a dificuldade de conseguir touros suficientemente bravos.

Em julho de 1821, o Senado da Câmara pela terceira vez anuncia que pretende arrematar o desmanche do curro. No Diário do Rio de Janeiro de $1^{\circ}$ de setembro de 1821 , Jacinto José da Cunha ${ }^{37}$ dá ciência ao público que concretizou o negócio, colocando à venda as madeiras, para construção ou para ser usada como lenha. Esse chamado, todavia, parece não ter surtido grande efeito, pelo menos na sua íntegra, já que José Martins Rocha, em nome do Senado da Câmara, ultima o arrematante a terminar a desmontagem, "sob pena de mandar fazer o mesmo à sua custa" (Diario do Rio de Janeiro, 1822, p. 1).

Segundo Oliveira Lima (2006, p. 570), nos seus últimos dias, a praça recebeu um circo onde atuava uma companhia de acrobatas e funâmbulos ingleses, "acudindo a população a rir estrepitosamente com os trejeitos dos palhaços, aplaudir os maravilhosos exercícios equestres de Mr. Southby e extasiar-se diante da corda bamba e dos equilíbrios de Mrs. Southby”. Pelo que foi possível saber, desde dezembro de 1818, a Companhia Inglesa de

${ }^{36}$ Negociante de sucesso, foi personagem de destaque no Rio de Janeiro das primeiras décadas do século XIX.

${ }^{37}$ A única informação que obtivemos sobre José Jacinto indica que era um comerciante que tinha relações com o norte do país e com Portugal. 
Cavalinhos já se apresentava na praça (Gazeta do Rio de Janeiro, 1818c, p. 4), mais um indício de que houve mesmo poucas corridas de touros promovidas por Florim.

James Henderson (1821), um diplomata inglês que viveu no Brasil entre os anos de 1819 e 1821, também observa que, nos últimos dois anos de funcionamento da praça, não houvera touradas, destacando-se mesmo as atuações da companhia de ingleses. Eles teriam dialogado com as peculiaridades locais e construído um espetáculo que encantava e deixava surpresa a população.

Mais um visitante, Gilbert Farquhar Mathison (1825, p. 11, tradução minha), que no Rio de Janeiro esteve em 1821, reforça essa informação: "Teatro é agora o único lugar público destinado ao entretenimento e, recentemente, cessaram as touradas." A arena e as corridas de touros se extinguiram no momento em que estavam prestes a ser definitivamente rompidos os laços coloniais entre Brasil e Portugal.

\section{Conclusão}

No Rio de Janeiro colonial, pelo menos até os últimos anos que antecederam a independência, as touradas estiveram diretamente relacionadas ao calendário da monarquia. Eram eminentemente uma iniciativa governamental, sendo para tal contratados profissionais para as mais distintas necessidades e funções que cercavam a sua realização, desde a construção do redondel até a atuação com os touros. As corridas seguiam um protocolo estabelecido pela tradição, à moda portuguesa, sendo realizadas em conjunto com outras atividades que integravam a programação das festividades públicas.

Vale ressaltar que a hierarquia social era demarcada não apenas pelo lugar que o público ocupava nas tribunas da praça de curro. A própria dinâmica do espetáculo reproduzia as distinções. No caso das touradas, a aristocracia estava representada na figura dos cavaleiros, enquanto o campesinato era representado na figura dos moços do forcado, que enfrentavam os touros sem armas. Ao mesmo tempo em que se via nos camarotes e arquibancadas, a sociedade se reconhecia na própria arena.

Devemos também ter em conta que, no Antigo Regime, política e divertimento não eram esferas de ocupação de tempo tão nitidamente separadas - o mesmo vale para o binômio religião-diversão. 
Muitos divertimentos públicos reproduziam esse aspecto, como era o caso das festas ordinárias e das festas reais. Certamente, havia entretenimentos livres dessa injunção, mas esse não era, a princípio, o caso das touradas. Eram espetáculos dispendiosos, que requeriam complexa organização, e não passatempos vulgares. O público tinha oportunidade de ir aos touros porque a monarquia fornecia esse gênero de diversão. Nas corridas de touros, não se divertia "apesar" da exibição dos reis, se divertia "com" a exibição dos reis (divertir-se não como sinônimo de fazer troça, mas de apreciar).

Há também que se ter em conta o vínculo existente entre um divertimento de origem rural e o caráter eminentemente rural do mundo colonial. O Rio de Janeiro desse período era uma pequena concentração urbana cercada de chácaras e fazendas. O público tinha grande familiaridade com cavalos e touros. Assim, o gosto pelas touradas não se produzia por contraste, mas por afinidade com a vida cotidiana.

É somente a partir dos anos 1830 que as touradas vão se autonomizar; isso é, vai constituir-se um campo da tauromaquia no Rio de Janeiro, conforme opera Luís Capucha (1988) ao dialogar com os conceitos de Pierre Bourdieu. As corridas passariam a ser eminentemente compreendidas como parte do campo dos entretenimentos públicos, que melhor se estruturará no país independente, notadamente na sua capital.

Isto é, a partir da década de 1830, as touradas adquiririam uma série de características até então não observáveis: a conformação de um corpo de especialistas relativamente estável, exclusivo e multifacetado (desde empresários e profissionais do toureio até, futuramente, jornalistas no tema especializados), o estabelecimento de um calendário que não se submete a necessidades estatais (as touradas serão realizadas de acordo com os interesses e desejos de promotores e público), a gestação de um mercado ao seu redor (movimentado com a cobrança de entradas, patrocínios e outras formas de geração de renda), o surgimento de entidades representativas (tanto de empresas a elas dedicadas quanto de clubes específicos). Nos anos finais do período colonial, as iniciativas nesse sentido, por motivos diversos, não lograram êxito.

Na verdade, mesmo em Portugal, como lembra Capucha (1988, p. 150), "a lide de toiros bravos remonta ao paleolítico. Não obstante, a tauromaquia enquanto produto cultural a cargo de um conjunto de especialistas, de funções variadas na 'festa', é um fenômeno relativamente recente." Segundo o autor, somente em 1776 apareceu o primeiro regulamento, isso é, passou "a 
ser um espectáculo que obedece a regras, que os especialistas devem cumprir" (Capucha, 1988, p. 151).

Devemos observar que as touradas integraram a programação dos festejos dedicados a celebrar a independência, realizadas após a aclamação de Pedro I, em 12 de outubro de 1822. Grande parte dos eventos, aliás, teve lugar no mesmo Campo de Santana, que a partir de então passa a se chamar Campo da Aclamação. Como sugerem Schwarcz, Costa e Azevedo (2002, p. 382):

Longe de serem apenas divertimentos passageiros, as festas de Independência se convertiam em rituais políticos endereçados ao povo, que assim reconhecia a separação entre Portugal e Brasil. É claro que lá todos se divertiam, e muito; mas era também por meio desses rituais que se dava visibilidade ao soberano e estabeleciam-se vínculos com a nova realidade política.

As touradas, uma prática tão ligada à Coroa portuguesa, integrando a comemoração de celebração do fim dos laços coloniais: curioso, mas não inusitado. A construção de uma identidade brasileira foi um longo processo, que passou pelo estabelecimento de novas relações com Portugal, e isso significava repensar o papel das práticas culturais a esse país relacionadas.

O importante é perceber que o sentido central das corridas de touros nesse primeiro momento, a declaração e a explicitação de vínculos de lealdade com a metrópole, manter-se-á sempre ativo ao redor da prática. No futuro, inclusive, será um dos elementos que colocará em xeque sua própria manutenção.

\section{Referências}

ALMEIDA, J. D. de. História da tauromaquia: técnica e evolução artística do toureio. Lisboa: Artis, 1951.

ALMEIDA, M. V. de. Marialvismo. Fado, touros e saudade como discursos da masculinidade, da hierarquia social e da identidade nacional. Trabalhos de Antropologia e Etnologia, v. 37, n. 1-2, p. 41-66, 1997.

ARQUIVO NACIONAL. Fundo Marquês do Lavradio: inventário. Rio de Janeiro: Arquivo Nacional, 1999. 
CALDEIRA, J. O processo econômico. In: SILVA, A. da C. (Coord.). História do Brasil Nação (1808-2010): volume 1: crise colonial e independência (18081830). Rio de Janeiro: Objetiva, 2011. p. 161-204.

CAPUCHA, L. O campo da tauromaquia. Sociologia, Problemas e Práticas, Lisboa, n. 5, p. 147-165, 1988.

CAVALCANTI, N. O Rio de Janeiro setecentista. Rio de Janeiro: Jorge Zahar, 2004.

CONDE, R. de L.; MASSIMI, M. Corpo, sentidos e coreografias: narrativas de uma festividade na Bahia do século XVIII. Psicologia em Revista, Belo Horizonte, v. 14, n. 1, p. 215-234, jun. 2008.

DIARIO DO RIO DE JANEIRO. Rio de Janeiro, 30 jan. 1822.

EDMUNDO, L. O Rio de Janeiro no tempo dos Vice-Reis. Belo Horizonte: Itatiaia, 2000.

FRAGOSO, J. A nobreza vive em bandos: a economia política das melhores famílias da terra do Rio de Janeiro, século XVII. Algumas notas de pesquisa. Tempo, Niterói, v. 8, n. 15, p. 11-35, 2003.

GARRIDO, F. de M. Produção, comércio e tensões nas vilas do norte da capitania de São Paulo (1788-1808). Dissertação (Mestrado em História)Faculdade de Ciências Humanas e Sociais, Universidade Estadual Paulista, Franca, 2012.

GAZETA DE LISBOA. Lisboa, n. 14, 16 jan. 1819.

GAZETA DO RIO DE JANEIRO. Rio de Janeiro, n. 80, 6 out. 1810a.

GAZETA DO RIO DE JANEIRO. Rio de Janeiro, n. 89, 7 nov. 1810 b.

GAZETA DO RIO DE JANEIRO. Rio de Janeiro, n. 8, 28 jan. 1818a.

GAZETA DO RIO DE JANEIRO. Rio de Janeiro, n. 82, 14 out. 1818b. 
GAZETA DO RIO DE JANEIRO. Rio de Janeiro, n. 102, 23 dez. 1818c.

GAZETA DO RIO DE JANEIRO. Rio de Janeiro, n. 3, 8 jan. 1820.

GOUVÊA, M. de F. S. Poder, autoridade e Senado da Câmara do Rio de Janeiro, ca. 1780-1820. Tempo, Niterói, v. 7, n. 13, p. 111-155, 2002.

GRAHAM, M. Diário de uma viagem ao Brasil e de uma estada nesse país durante parte dos anos de 1821, 1822 e 1823. São Paulo: Companhia Editora Nacional, 1956.

HANSEN, J. A. A categoria "representação" nas festas coloniais dos séculos XVII e XVIII. In: JANCSÓN, I.; KANTOR, I. (Org.). Festa: cultura e sociabilidade na América portuguesa. São Paulo: Hucitec, 2001. p. 735-758.

HENDERSON, J. A history of Brazil. London: Longman, Hurst, Rees, Orme and Brown, 1821.

HONORATO, C. de P. O mercado de escravos do Rio de Janeiro, 1758 a 1831. Dissertação (Mestrado em História)-Instituto de Ciências Humanas e Filosofia, Universidade Federal Fluminense, Niterói, 2008.

KANTOR, I. Festas públicas e processo colonizador: as festas de comemoração da conquista do Tibagi na segunda metade do século XVIII. Politeia: História e Sociedade, Vitória da Conquista, v. 8, n. 1, p. 165-177, 2008.

LARA, S. H. Fragmentos setecentistas: escravidão, cultura e poder na América portuguesa. São Paulo: Companhia das Letras, 2007.

LEITHOLD, T. V.; RANGO, L. V. O Rio de Janeiro visto por dois prussianos em 1819. São Paulo: Companhia Editora Nacional, 1966.

LUCCOCK, J. Notas sobre o Rio de Janeiro e partes meridionais do Brasil. Belo Horizonte: Itatiaia, 1987.

MARROCOS, L. J. dos S. Cartas do Rio de Janeiro - 1811-1821. Lisboa: Biblioteca Nacional de Portugal, 2008. 
MARTINS, M. de S. N. Entre a cruz e o capital: as corporações de ofícios após a chegada da família real (1808-1824). Rio de Janeiro: Garamond, 2008.

MATHISON, G. F. Narrative of a visit to Brazil, Chile, Peru, and the Sandwich islands, during the years 1821 and 1822. London: Charles Knight, 1825.

MORAES FILHO, M. Os ciganos no Brasil e cancioneiro dos ciganos. Belo Horizonte: Itatiais; São Paulo: USP, 1981.

MOURA FILHA, M. B. Festas e celebrações no Brasil colonial: representações de poder e elos de ligação com a cultura portuguesa do século XVIII. In: SIMPÓSIO NACIONAL DE HISTÓRIA, 24., 2007, São Paulo. Anais... São Paulo: Anpuh, 2007. Disponível em: <http://anpuh.org/anais/wp-content/ uploads/mp/pdf/ANPUH.S24.0311.pdf > . Acesso em: 5 nov. 2012.

NORTON, L. A corte de Portugal no Brasil. São Paulo: Companhia Editora Nacional, 2008.

OLIVEIRA LIMA, M. de. D. João VI no Brasil. Rio de Janeiro: Topbooks, 2006.

PAES, M. P. D. C. O teatro do controle: o domínio social e político na América Portuguesa da primeira metade do século XVIII. Nuevo Mundo, Mundos Nuevos. Colóquios, 2008. Disponível em: $<\mathrm{http}: / /$ nuevomundo.revues. org/21862>. Acesso em: 5 nov. 2012.

PEREIRA, S. G. A representação do poder real e as festas públicas no Rio de Janeiro colonial. In: BARROCO: Actas do II Congresso Internacional. Porto: Universidade do Porto, 2004. p. 663-678. Disponível em: $<$ http://ler.letras. up.pt/uploads/ficheiros/7520.pdf>. Acesso em: 5 nov. 2012.

PORTO, M. B. G. B. Nobres poderes: a atuação do Senado da câmara fluminense na economia e os privilégios e deveres dos Homens Bons (17901807). Dissertação (Mestrado em História)-Instituto de Ciências Humanas e Filosofia, Universidade Federal Fluminense, Niterói, 2011. 
RELAÇÃO DAACCLAMAÇÃO que se fez na Capitania do Rio de Janeiro, do Estado do Brasil, e nas mais do Sul, ao Senhor Rei D. João IV, por verdadeiro Rei e Senhor do seu Reino de Portugal, com a felicissima restituição que d'elle se fez a Sua Magestade, que Deus Guarde, etc. Revista Trimensal de História e Geographia: ou Jornal do Instituto Historico Geographico Brazileiro, Rio de Janeiro, n. 19, p. 343-352, out. 1843.

RELAÇÃO DOS OBSEQUIOSOS festejos, que se fizeram na Cidade de Sebastião do Rio de Janeiro, pela plausível notícia do Nascimento do Sereníssimo Senhor Príncipe da Beira, o Senhor D. José. No ano de 1762, oferecida ao nobilíssimo Senado da mesma Cidade, que tão generosamente concorreu para estes grandes festejos, em que se empenhou a sua fidelidade, e desempenhou seu afeto. Por um seu Cidadão e Anônimo. Lisboa: Oficina Patriarcal de Francisco Luiz Ameno, 1763.

SANTOS, L. G. dos. Memórias para servir à História do Reino do Brasil. Belo Horizonte: Itatiaia: São Paulo: Edusp, 1981.

SCHULTZ, K. Perfeita civilização: a transferência da corte, a escravidão e o desejo de metropolizar uma capital colonial. Rio de Janeiro, 1808-1821. Tempo, Niterói, v. 12, n. 24, p. 5-27, 2008.

SCHWARCZ, L. M.. Cultura. In: SILVA, A. da C. (Coord.). História do Brasil Nação (1808-2010): volume 1: crise colonial e independência (1808-1830). Rio de Janeiro: Objetiva, 2011. p. 205-248.

SCHWARCZ, L. M.; COSTA A. M. da; AZEVEDO P. C. de. A longa viagem da biblioteca dos reis: do terremoto de Lisboa à Independência do Brasil. São Paulo: Companhia das Letras, 2002.

SEGAWA, H. Ao amor do público: jardins no Brasil. São Paulo: Studio Nobel; Fapesp, 1996.

SILVA, M. B. N. da. Cultura e sociedade no Rio de Janeiro (1808-1821). São Paulo: Companhia Editora Nacional, 1978. 
SILVA, M. B. N. da. Ser nobre na colônia. São Paulo: Unesp, 2005.

VIEIRA FAZENDA, J. Antiqualhas e memórias do Rio de Janeiro. Rio de Janeiro: Imprensa Nacional, 1921.

Recebido em: 26/12/2012

Aprovado em: 04/06/2013 